\title{
Effect of Mitiglinide on Glycemic Control over 52 Weeks in Japanese Type 2 Diabetic Patients Insufficiently Controlled with Pioglitazone Monotherapy
}

\author{
KoHEI KAKU*, SHUN-ICHI TANAKA**, HideKI ORIGASA***, MASATOSHI KIKUCHI ${ }^{*}$ AND YASUO AKANUMA* \\ *Diabetes and Endocrine Division, Department of Medicine, Kawasaki Medical School, Kurashiki, Okayama, Japan \\ **Kanazawa Medical Clinic, Kanazawa-ku, Yokohama, Kanagawa, Japan \\ ***University of Toyama Graduate School of Medicine and Pharmaceutical Sciences, Toyama, Japan \\ ${ }^{\#}$ Institute of Adult Disease, Asahi Life Foundation, Chiyoda-ku, Tokyo, Japan
}

\begin{abstract}
This study was performed to examine the efficacy and safety of the rapid- and short-acting insulinotropic SUR ligand mitiglinide given as add-on therapy for 52 weeks in type 2 diabetic patients whose blood glucose was insufficiently controlled by pioglitazone monotherapy. Type 2 diabetic patients aged $\geq 20$ years with postprandial plasma glucose (PPG1 or 2) $\geq 200 \mathrm{mg} / \mathrm{dL}$ and glycated hemoglobin $\left(\mathrm{HbA}_{1 \mathrm{C}}\right) 6.5-<9.0 \%$ despite receiving pioglitazone $15-45 \mathrm{mg} /$ day were additionally treated with concomitant mitiglinide $10 \mathrm{mg}$ tid p.o. for a total treatment period of 52 weeks. In 171 patients recruited, $\mathrm{HbA}_{1 \mathrm{C}}$ was significantly reduced from $7.64 \pm 0.77 \%$ at baseline to $6.84 \pm 0.73 \%, 6.64 \pm 0.64 \%, 6.67 \pm 0.57 \%$ and $6.81 \pm 0.65 \%$ at weeks $16,28,40$, and 52 , respectively. Over half the patients achieved $\mathrm{HbA}_{1 \mathrm{C}} \operatorname{target}$ of $<7.0 \%$, and one third $<6.5 \%$. Significant reductions in fasting plasma glucose (FPG) and PPG 1 and 2 hours after a meal versus baseline were noted at all time-points evaluated. The most frequently noted adverse reactions were hypoglycemic symptoms, weight gain, and peripheral edema (all mild). In type 2 diabetic patients combination therapy with mitiglinide and pioglitazone exerted significant long-term improvements in $\mathrm{HbA}_{1 \mathrm{C}}$, FPG, and PPG and was well tolerated. This drug combination therapy is a promising means of alleviating insufficient pancreatic insulin secretion and insulin resistance.
\end{abstract}

Key words: Type 2 diabetes, Mitiglinide, Pioglitazone, Combination therapy

(Endocrine Journal 56: 739-746, 2009)

TYPE 2 diabetes mellitus is a syndrome involving insufficient insulin secretion from pancreatic $\beta$-cells and insulin resistance in peripheral tissues [1]. Patients with this disease often have postprandial hyperglycemia because rapid additional secretion of insulin after meals is insufficient, and a vicious circle of glucotoxicity leading to protracted and advanced hyperglycemia arises when this condition continues.

It has become clear from large-scale clinical studies that postprandial hyperglycemia is a risk factor for arteriosclerosis independent of hypertension and hy-

Received Jan. 23, 2009; Accepted May 1, 2009 as K09E-023 Released online in J-STAGE as advance publication Jun. 9, 2009

Correspondence to: Kohei KAKU, M.D., Ph.D., Diabetes and Endocrine Division, Department of Medicine, Kawasaki Medical School, 577 Matsushima, Kurashiki, Okayama 701-0192, Japan. E-mail:kka@med.kawasaki-m.ac.jp perlipidemia $[2,3]$. In the STOP-NIDDM trial [4] it was shown that improvement in postprandial hyperglycemia exerted by $\alpha$-glucosidase inhibitors in patients with impaired glucose tolerance (IGT) delays the onset of cardiovascular events, and the importance of correction of postprandial hyperglycemia on limiting the progression of diabetes as well as preventing the onset of macrovascular diseases was thus suggested.

At present, sulfonylurea (SU) agents and rapid- and short-acting insulinotropic SU receptor (SUR) ligands are used to supplement insufficient insulin secretion in type 2 diabetic patients. SU agents have strong hypoglycemic actions, but are ineffective at promoting additional secretion of insulin after meals. In addition, these agents are known to induce protracted hypoglycemia and obesity is a problem associated with their use. Mitiglinide is a new rapid- and short-acting insulinotropic SUR ligand, a benzylsuccinic acid deriva- 
tive developed in Japan, which features rapid hypoglycemic action unlike SU agents [5-7]. It alleviates postprandial hyperglycemia and as a result improves glycemic control as a whole [8]. Since the blood concentration rapidly rises after oral administration then quickly disappears, the drug is thought unlikely to exert hypoglycemic effects early in the morning and between meals. Moreover, mitiglinide shows potent affinity to and selective action on the $\mathrm{K}_{\mathrm{ATP}}$ channel (Kir6.2/SUR1) [9], suggesting that it acts specifically on pancreatic $\beta$-cells to secrete insulin and has few unwanted effects on the cardiovascular system.

Pioglitazone, a thiazolidinedione derivative, is a hypoglycemic agent that improves insulin resistance and is widely used in the treatment of type 2 diabetes. In postmarketing studies [10] and large-scale clinical studies [11] performed in recent years, it was reported that pioglitazone elicits safe glycemic control and inhibits the onset of cardiovascular disorders.

The present study was performed to examine the efficacy and safety of mitiglinide given as add-on therapy for 52 weeks in type 2 diabetic patients who were insufficiently controlled by pioglitazone monotherapy.

\section{Materials and Methods}

\section{Patients}

Included in this study were Japanese type 2 diabetic patients aged $\geq 20$ years who did not show adequate glycemic control defined as having a 1- or 2-hour postprandial glucose (PPG1 or PPG2) value $\geq 200 \mathrm{mg}$ / $\mathrm{dL}$ with a meal of $400 \mathrm{kcal}$ despite receiving treatment for $\geq 8$ weeks ( 56 days) with pioglitazone monotherapy at a fixed dose $(15,30$, or $45 \mathrm{mg} /$ day) in addition to diet therapy and whose glycated hemoglobin $\left(\mathrm{HbA}_{1 \mathrm{C}}\right)$ at screening visit (week -4 ) was $6.5-<9.0 \%$. Patients with a history of treatment with pioglitazone and highdose SU agents within 24 weeks (168 days) before screening and those requiring insulin therapy were excluded, as were patients with severe diabetic complications (neuropathy, retinopathy, and nephropathy), severe liver disease, renal dysfunction, hypertension, and heart disease.

This study was performed in compliance with GCP; all subjects provided written informed consent to participate prior to its commencement. Appropriate institutional review boards approved the study.

\section{Study design}

This was an open label study that consisted of a pretreatment observation period lasting 4 weeks and a 52-week treatment period. During the 4-week observation period, a fixed dose of pioglitazone $(15,30$, or $45 \mathrm{mg} /$ day) was administered orally before or after breakfast. Eligible patients who met the inclusion criteria during the observation period then continued pioglitazone monotherapy at the same dosage and additionally received mitiglinide $10 \mathrm{mg}$ tid po immediately (within $5 \mathrm{~min}$ ) before each meal. Thereafter, if $\mathrm{HbA}_{1 \mathrm{C}}$ after 12 weeks of continuous administration did not reach the target value $(<7.0 \%$ if $\geq 7.0 \%$ at start of administration [week 0] or $<6.5 \%$ if $<7.0 \%$ at week 0 ), the dosage of mitiglinide could be increased to 20 $\mathrm{mg}$ tid from week 16 so as to attempt further improvement. On the other hand, if the physician judged that mitiglinide $10 \mathrm{mg}$ tid presented a safety problem, it could be reduced to $5 \mathrm{mg}$ tid.

During both the observation and treatment periods concomitant use of oral hypoglycemic agents other than the test agents and insulin products was prohibited whereas administration and dosage of drugs used from before the study for treatment of complications was not changed whenever possible.

Patient characteristics were examined at screening (week -4). $\mathrm{HbA}_{1 \mathrm{C}}$, FPG, hematology, blood chemistry and urinalysis values, body weight, and blood pressure were assessed every 4 weeks from week -4 to week 52. PPG1 and PPG2 were measured at weeks $-4,16$, 28 , and 52 . The meal tolerance test at screening was performed by administration of pioglitazone and from after week 16 by that of pioglitazone plus mitiglinide.

\section{Study evaluations}

Efficacy endpoints were $\mathrm{HbA}_{1 \mathrm{C}}$, change in $\mathrm{HbA}_{1 \mathrm{C}}$ at each evaluation point from that measured at week 4 after addition of mitiglinide, therapeutic achievement rate of $\mathrm{HbA}_{1 \mathrm{C}}$ target, and measured values of and changes in FPG, PPG1, and PPG2.

Safety endpoints were incidence rates of adverse events including hypoglycemic episodes and adverse drug reactions.

\section{Statistical analysis}

Summary statistics were calculated for efficacy and 


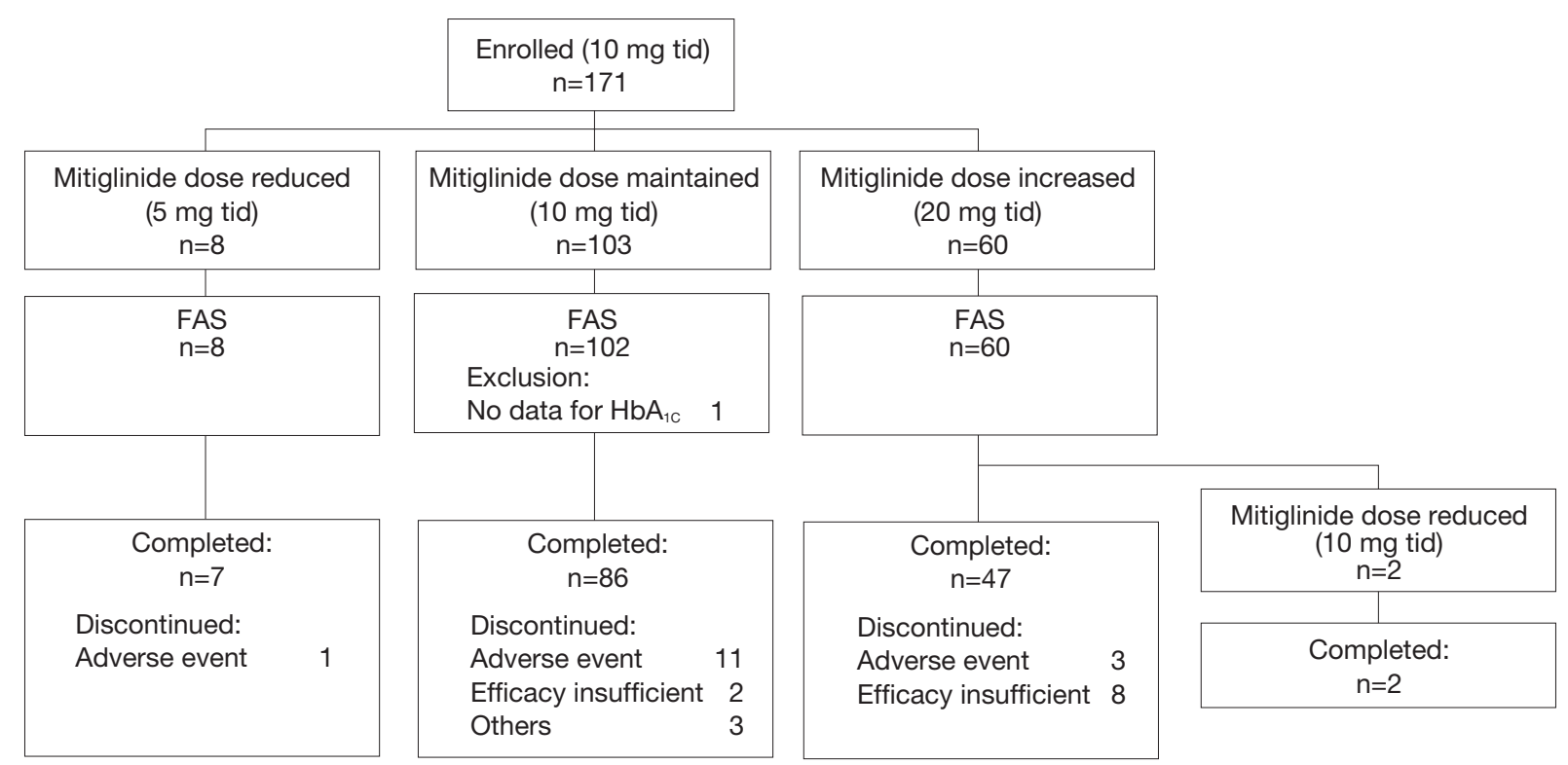

Fig. 1. Patients' disposition

safety endpoints. Intragroup comparisons of $\mathrm{HbA}_{1 \mathrm{C}}$ were performed by one-sample t-test with week 0 values as control. Therapeutic achievement rate of $\mathrm{HbA}_{1 \mathrm{C}}$ target was assessed by calculating two-sided $95 \%$ CI. Summary statistics of measured values of FPG, PPG1, and PPG2 from week -4 were calculated, and changes in these parameters from week 4 were also compiled as summary statistics. Intragroup comparison was performed by one-sample t-test with week -4 (PPG1 and PPG2) or week 0 (FPG) values as control.

\section{Results}

\section{Patients}

Figure 1 shows the disposition of patients in this study. A total of 171 patients were eligible for enrollment in this study and received test medication; they included 103 patients who maintained a mitiglinide dosage of $10 \mathrm{mg}$ tid until completion of the study, 8 patients whose dosage was decreased to $5 \mathrm{mg}$ tid, and 60 patients who were increased to $20 \mathrm{mg}$ tid. Ten patients discontinued due to insufficient effects; 9 discontinued because $\mathrm{HbA}_{1 \mathrm{C}}$ was $>8.0 \%$ at 2 consecutive measurements after week 28 despite a dose increase to $20 \mathrm{mg}$ (one of the study withdrawal criterions), and 1 withdrew after mitiglinide $10 \mathrm{mg}$ did not achieve target $\mathrm{HbA}_{1 \mathrm{C}}$ level, but was not then increased to $20 \mathrm{mg}$
Table 1. Patient baseline characteristics

\begin{tabular}{|c|c|}
\hline Parameter & $\mathrm{n}($ or mean $\pm \mathrm{SD})$ \\
\hline No. of patients & 170 \\
\hline Sex, Male/Female & $120 / 50$ \\
\hline Age, years & $60.1 \pm 10.1$ \\
\hline \multicolumn{2}{|l|}{ Pioglitazone dosage, mg/day } \\
\hline 15 & 79 \\
\hline 30 & 91 \\
\hline 45 & - \\
\hline BMI, $\mathrm{kg} / \mathrm{m}^{2}$ & $25.33 \pm 4.33$ \\
\hline Duration of diabetes, years & $6.6 \pm 5.8$ \\
\hline $\mathrm{HbA}_{1 \mathrm{C}}, \%$ & $7.64 \pm 0.77$ \\
\hline FPG, mg/dL & $160.1 \pm 27.4$ \\
\hline PPG1, mg/dL & $269.0 \pm 40.7$ \\
\hline $\mathrm{PPG} 2, \mathrm{mg} / \mathrm{dL}$ & $253.5 \pm 56.8$ \\
\hline Fasting serum insulin, $\mu \mathrm{U} / \mathrm{mL}$ & $7.807 \pm 5.934$ \\
\hline Adiponectin, $\mu \mathrm{g} / \mathrm{mL}$ & $16.13 \pm 9.88$ \\
\hline
\end{tabular}

BMI, body mass index; FPG, fasting plasma glucose; PPG1, postprandial plasma glucose at 1 hour after a meal; PPG2, postprandial plasma glucose at 2 hours after a meal.

as specified in the study protocol because of hypoglycemic symptoms during administration of mitiglinide $10 \mathrm{mg}$. One patient who maintained a dose of 10 mg tid was excluded from the full analysis set (FAS) because evaluable $\mathrm{HbA}_{1 \mathrm{C}}$ data were missing. In the FAS, 142 patients completed 52 weeks of treatment.

Table 1 shows the patient characteristics as demographic statistics in the FAS, the main population for the efficacy analysis. 


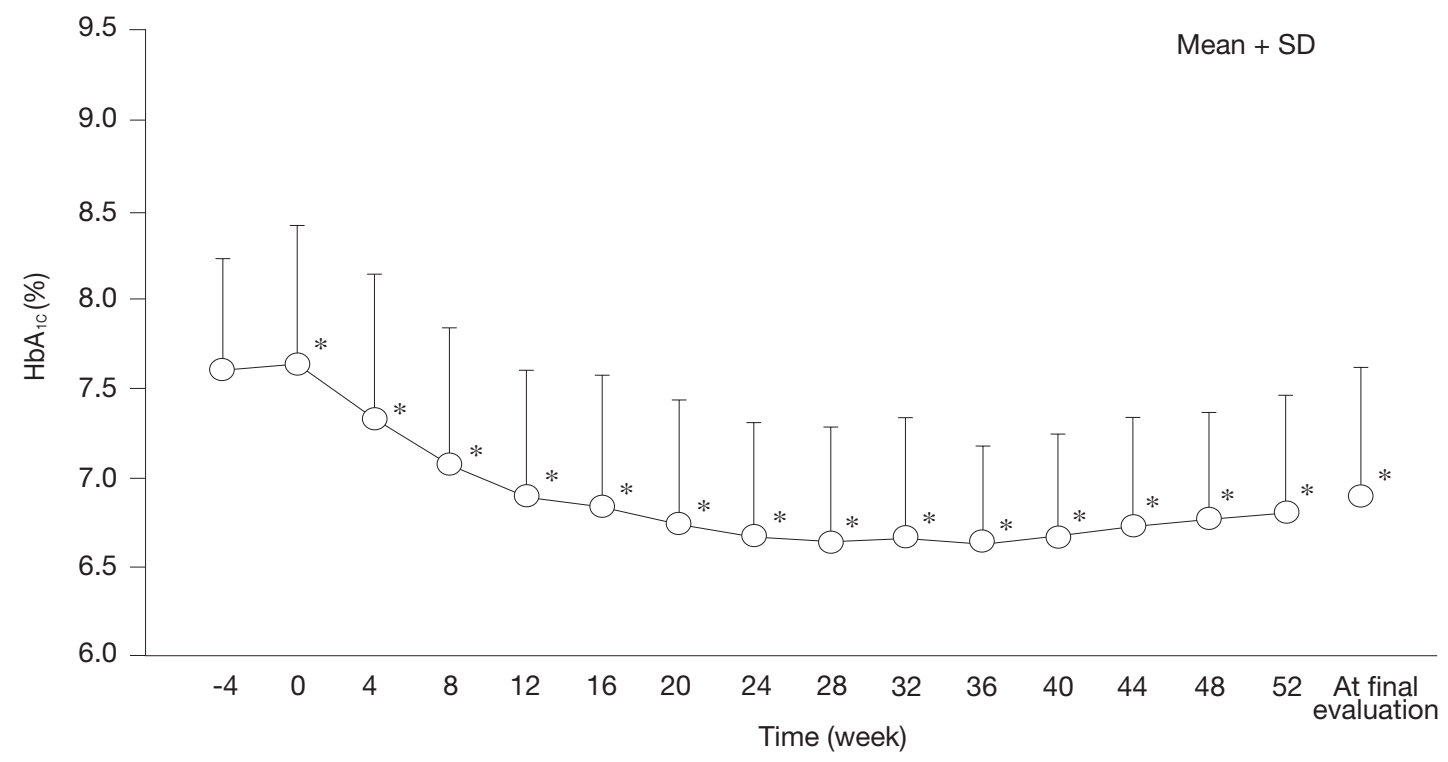

Fig. 2. Time-course of changes in $\mathrm{HbA}_{1 \mathrm{C}}{ }^{*} p<0.001$.

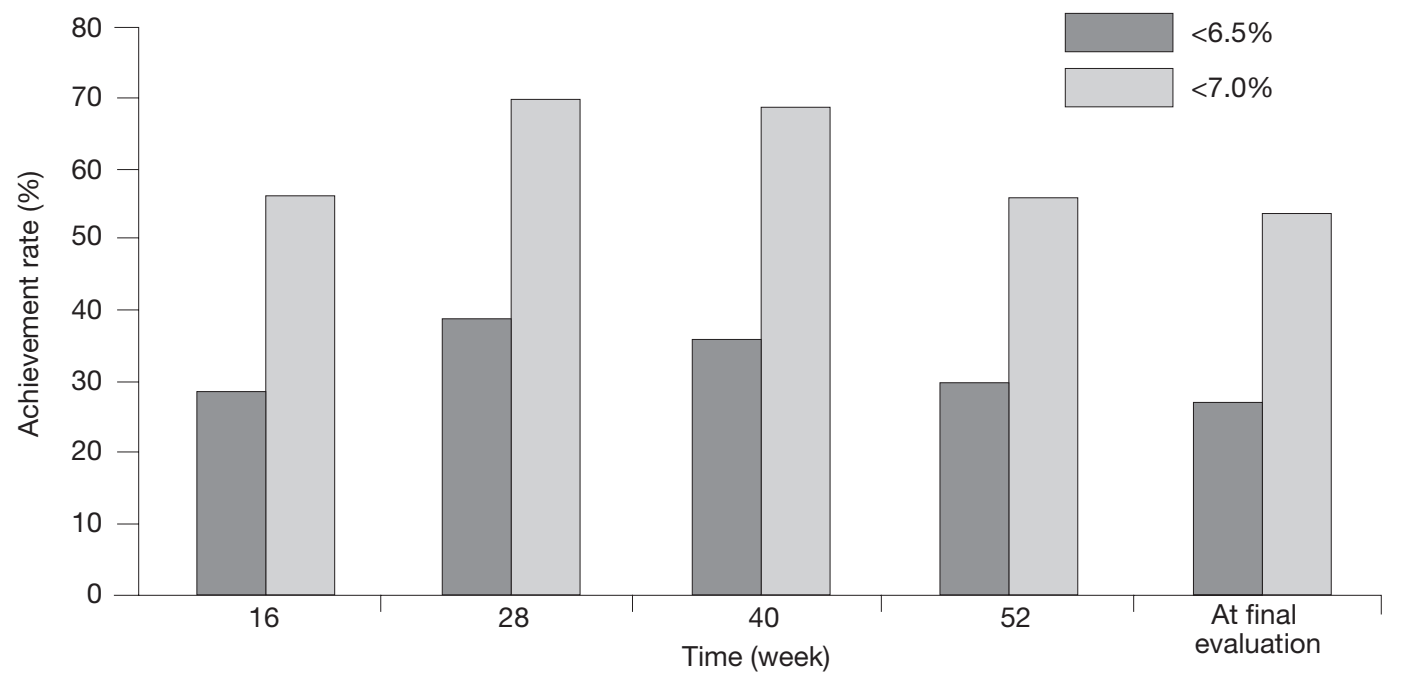

Fig. 3. Achievement rate of $\mathrm{HbA}_{1 \mathrm{C}}$ targets $<7.0 \%$ and $<6.5 \%$.

\section{Efficacy}

Figure 2 shows the time-course of $\mathrm{HbA}_{1 \mathrm{C}}$ in the FAS. At screening (week -4) and baseline (week 0), $\mathrm{HbA}_{1 \mathrm{C}}$ was $7.61 \pm 0.61 \%$ and $7.64 \pm 0.77 \%$, respectively, whereas at weeks $16,28,40$, and $52 \mathrm{HbA}_{1 \mathrm{C}}$ was reduced to $6.84 \pm 0.73 \%, 6.64 \pm 0.64 \%, 6.67 \pm$ $0.66 \%$, and $6.81 \pm 0.65 \%$, respectively. Addition of mitiglinide to pioglitazone therapy exerted significant reductions in this parameter starting from week 4 and persistently thereafter until the end of the 52-week treatment period.

The percentage of patients whose $\mathrm{HbA}_{1 \mathrm{C}}$ reached therapeutic target levels at each evaluation is shown in Figure 3. Throughout the study, achievement rate of $\mathrm{HbA}_{1 \mathrm{C}}<7.0 \%$ ranged from $53.6-69.8 \%$ whereas that of the $<6.5 \%$ target was $27.1-38.6 \%$.

Change in $\mathrm{HbA}_{1 \mathrm{C}}$ in patients stratified by their final dose of mitiglinide is shown in Figure 4. In the 104 patients who were maintained at the $10-\mathrm{mg}$ dose throughout the study (baseline $\mathrm{HbA}_{1 \mathrm{C}}, 7.42 \pm 0.65$ ) reduction in $\mathrm{HbA}_{1 \mathrm{C}}$ at weeks $16,28,40$, and 52 was 
Table 2. Baseline and mean change in fasting plasma glucose (FGP) and postprandial plasma glucose at 1 hour (PPG1) and 2 hour (PPG2) after a meal at weeks 16, 28, and 52 and final evaluation

\begin{tabular}{|c|c|c|c|c|c|c|}
\hline & \multicolumn{2}{|c|}{$\mathrm{FPG}, \mathrm{mg} / \mathrm{dL}$} & \multicolumn{2}{|c|}{ PPG1, mg/dL } & \multicolumn{2}{|c|}{ PPG2, mg/dL } \\
\hline & Change & $p$ value & Change & $p$ value & Change & $p$ value \\
\hline Week 16 & $-20.0 \pm 24.0$ & $<0.001$ & $-58.5 \pm 38.0$ & $<0.001$ & $-57.8 \pm 48.4$ & $<0.001$ \\
\hline Week 28 & $-23.5 \pm 24.5$ & $<0.001$ & $-64.2 \pm 42.3$ & $<0.001$ & $-63.6 \pm 50.4$ & $<0.001$ \\
\hline Week 52 & $-16.9 \pm 27.2$ & $<0.001$ & $-57.8 \pm 43.9$ & $<0.001$ & $-54.9 \pm 54.8$ & $<0.001$ \\
\hline Final evaluation & $-17.2 \pm 29.0$ & $<0.001$ & $-57.5 \pm 45.9$ & $<0.001$ & $-54.3 \pm 54.7$ & $<0.001$ \\
\hline
\end{tabular}

(A)

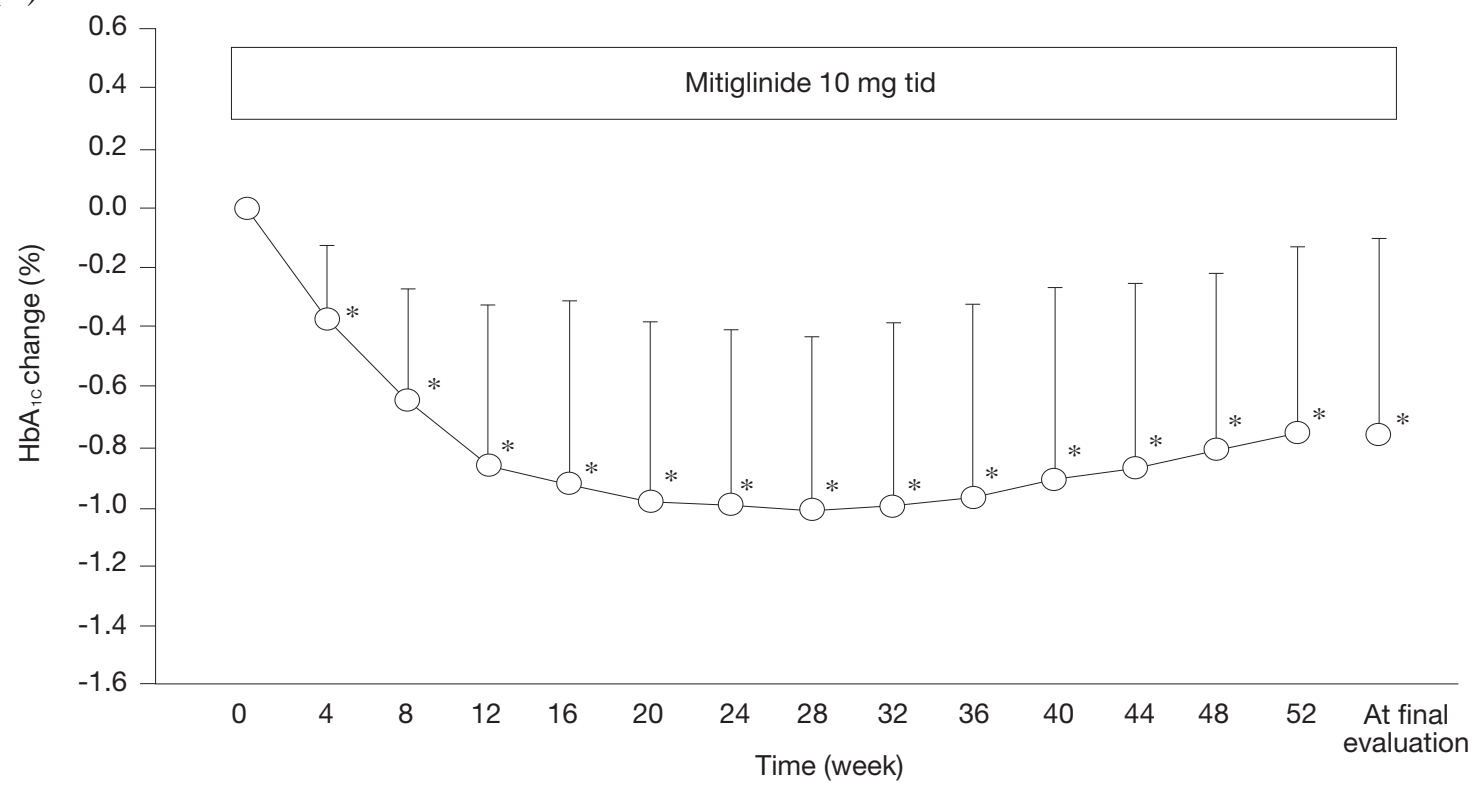

(B)

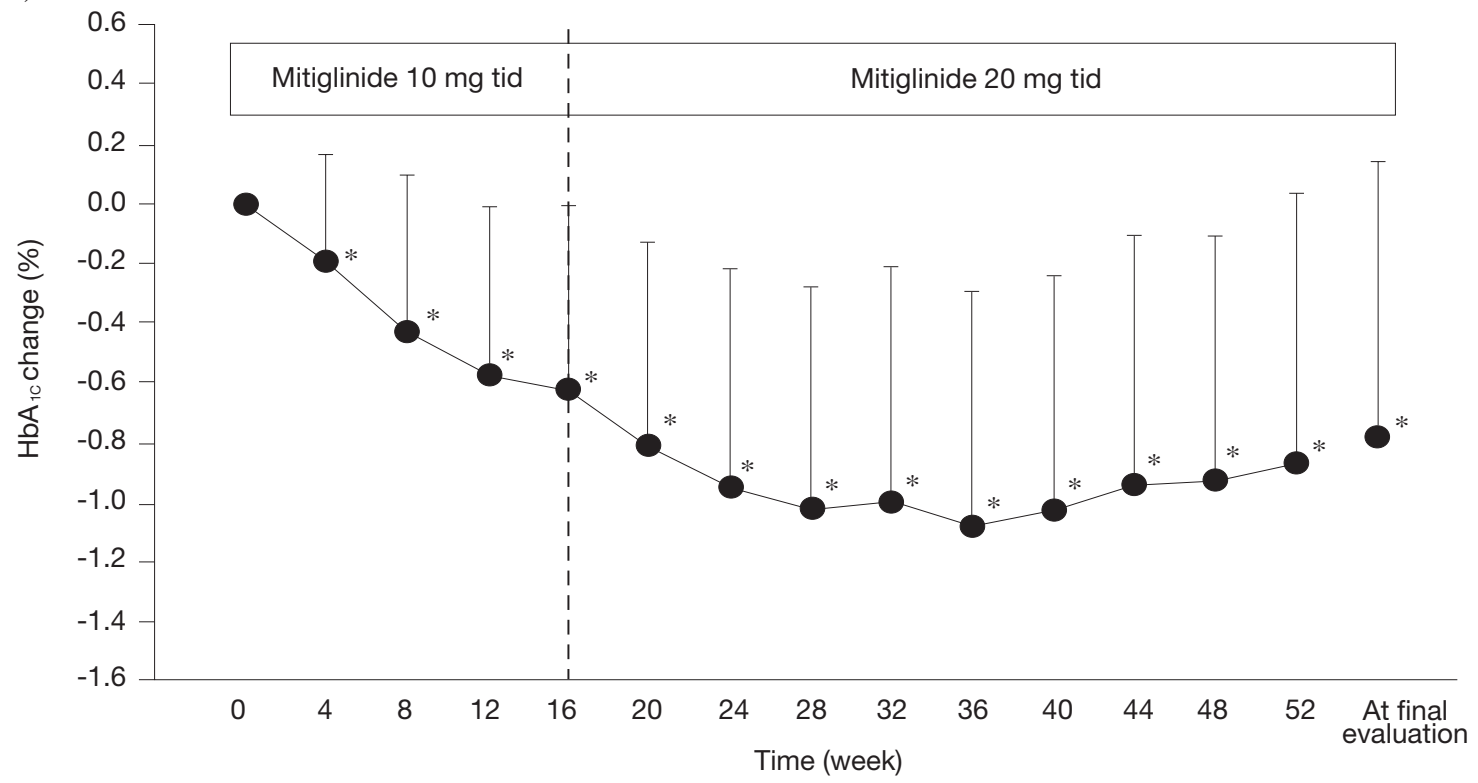

Fig. 4. Subgroup analysis of change in $\mathrm{HbA}_{1 \mathrm{C}}$ in patients who were maintained at mitiglinide $10 \mathrm{mg}$ tid (A) and who did not achieve target levels and whose dosage was increased to $20 \mathrm{mg}$ tid at 16 weeks (B). ${ }^{*} p<0.001$. 
$-0.92 \pm 0.61 \%,-1.01 \pm 0.58 \%,-0.91 \pm 0.65 \%$, and $-0.75 \pm 0.62 \%$, respectively (all $p<0.001$; Fig. 4A). Whereas, in those whose dose was up-titrated to the $20-\mathrm{mg}$ dose $\left(\mathrm{n}=58\right.$; baseline $\left.\mathrm{HbA}_{1 \mathrm{C}}, 8.13 \pm 0.76 \%\right)$, although the change in $\mathrm{HbA}_{1 \mathrm{C}}$ at week $16(-0.63$ $\pm 0.62 \%$ ) was lower than that observed in patients whose dose was maintained at $10 \mathrm{mg}$, significant ( $p$ $<0.001$ ) changes in $\mathrm{HbA}_{1 \mathrm{C}}$ were noted following dose increase $(-1.02 \pm 0.74 \%,-1.03 \pm 0.79 \%$, and $-0.87 \pm$ $0.91 \%$ at weeks 28, 40, and 52, respectively; Fig. 4B).

As shown in Table 2, significant reductions in FPG, PPG1, and PPG2 versus baseline were noted at all time-points evaluated.

\section{Safety}

In this study a total of 15 patients discontinued due to adverse events. Of these patients, 9 experienced adverse drug reactions of which a causal relation to mitiglinide could not be ruled out. Among them, 6 patients discontinued before week 16 of mitiglinide treatment and 3 at week 16 or later. Adverse drug reactions that caused discontinuation were "edema" in 3 patients; "increased AST" and "increased ALT"; "pancreatic carcinoma" ("metastases to liver"); "palpitations" and "thirst"; "pain"; "constipation," "insomnia," and "dry tongue"; and "edema," "weight gain," and "increased BNP" in 1 patient each.

The overall incidence of adverse drug reactions was $57.3 \%$, with clinical symptoms and abnormal laboratory findings noted in $41.5 \%$ and $33.9 \%$, respectively. Adverse clinical symptoms with an incidence of $\geq 3.0 \%$ included hypoglycemic symptoms such as dizziness, cold sweats and feeling abnormal, weight gain, and peripheral edema; abnormal laboratory findings occurring in $\geq 3.0 \%$ included elevated brain natriuretic peptide (BNP), creatine kinase (CK), and urine occult blood. Sixty-two of 68 hypoglycemic symptoms were judged mild, as were most weight gain (15/16 events) and eyelid, face, and peripheral edema (21/23 events). Mean body weight increased by approximately $1.3 \mathrm{~kg}$ from $67.2 \pm 13.3 \mathrm{~kg}$ at baseline to $68.5 \pm 13.3 \mathrm{~kg}$ at 52 weeks, and no severe edema was reported.

Increased BNP (15.4\%) and increased CK (5.9\%) although relatively frequent were not in the range that would cause clinical problems.

\section{Discussion}

The aim of treatment in most patients with type 2 diabetes mellitus is to improve both insufficient insulin secretion and insulin resistance and thereby achieve glycemic control. Based on encouraging data we obtained in a previous 16-week, double blind study (manuscript in preparation) this study was performed to investigate the efficacy and safety of adding mitiglinide $10 \mathrm{mg} /$ day to the regimens of patients on pioglitazone monotherapy over a long treatment period.

We observed significant improvement in $\mathrm{HbA}_{1 \mathrm{C}}$, the main efficacy endpoint, starting from week 4 of administration through to study end. Change in $\mathrm{HbA}_{1 \mathrm{C}}$ at weeks 28 and 52 was $-1.01 \pm 0.65 \%$ and $-0.78 \pm$ $0.73 \%$, respectively; thus long-term improvement of this parameter was confirmed. It was also possible to achieve American Diabetes Association [12]-recommended $\mathrm{HbA}_{1 \mathrm{C}}$ target of $<7.0 \%$ in over half our patients and $<6.5 \%$ in about one third.

With the addition of mitiglinide to pioglitazone, not only improvement in $\mathrm{HbA}_{1 \mathrm{C}}$ but also amelioration of postprandial hyperglycemia was confirmed and this beneficial effect continued for 52 weeks. It has been reported that intermittent hyperglycemia (glucose spikes) induces apoptosis of vascular endothelial cells when compared with persistent hyperglycemia [13] and that mitiglinide inhibits markers of oxidative stress and inflammation caused by postprandial hyperglycemia [14]. Continuous improvement in postprandial hyperglycemia over the long term as confirmed in this study is considered highly significant clinically. Postprandial hyperglycemia has also been reported as a primary factor affecting glycemic control in mildto-moderate type 2 diabetic patients [15]; therefore its alleviation from an early stage of the disease is considered important in preventing progression to more severe diabetes.

In the safety evaluation in this study, the hypoglycemic symptoms in this study were mostly mild (62/68 incidents) and presented no clinical problems. Furthermore, the appearance of hypoglycemic symptoms did not increase along with the period of administration of mitiglinide.

Weight gain, which often presents a problem associated with glitazone and SU agents, was about 1.3 $\mathrm{kg}$ over 52 weeks of combination therapy, which is mild compared with published reports of weight gain amounting to $2-6 \mathrm{~kg}$ associated with combinations of 
a rapid- and short-acting insulinotropic SUR ligand and thiazolidinedione derivative to improve insulin resistance [16-18]. Edema observed in this study was mostly mild (21/23 incidents) and did not present any clinical problem. Since no dose-dependent increase in edema was found in a previous study of mitiglinide, there appears almost no risk that adding this agent to pioglitazone regimens will cause this unwanted event.

The above findings indicate that in type 2 diabetic patients with insufficient pancreatic insulin secretion and insulin resistance as main presenting features, combination therapy with mitiglinide and pioglitazone aimed at alleviating both of these pathologies is a promising therapeutic strategy that evokes long-term improvement in $\mathrm{HbA}_{1 \mathrm{C}}$, PPG, and FPG.

\section{Acknowledgments}

This study was designed by Kissei Pharmaceutical Company and funded by Kissei and Takeda pharmaceutical companies.

\section{References}

1. Weyer C, Bogardus C, Mott DM, Pratley RE (1999) The natural history of insulin secretory dysfunction and insulin resistance in pathogenesis of type 2 diabetes mellitus. J Clin Invest 104: 784-794.

2. DECODE Study Group (1999) Glucose tolerance and mortality: comparison of WHO and American Diabetes Association diagnostic criteria. Lancet 354: 617-621.

3. Tominaga M, Eguchi H, Manaka H, Igarashi K, Kato T, Sekikawa A (1999) Impaired glucose tolerance is a risk factor for cardiovascular disease, but not impaired fasting glucose. The Funagata Diabetes Study. Diabetes Care 22: 920-924.

4. Hanefeld M, Cagatay M, Petrowitsch T, Neuser D, Petzinna D, Rupp M (2004) Acarbose reduces the risk for myocardial infarction in type 2 diabetic patients: meta-analysis of seven long-term studies. Eur Heart $J$ 25: $10-16$.

5. Ohnota H, Koizumi T, Tsutsumi N, Kobayashi M, Inoue S, Sato F (1994) Novel rapid- and short-acting hypoglycemic agent, a calcium (2s)-2-benzyl-3-(cishexahydro-2- isoindolinylcarbonyl) propionate (KAD1229) that acts on the sulfonylurea receptor: comparison of effects between KAD-1229 and gliclazide. $J$ Pharmacol Exp Ther 269: 489-495.

6. Mogami H, Shibata H, Nobusawa R, Ohnota H, Satou F, Miyazaki J, Kojima I (1994) Inhibition of ATPsensitive $\mathrm{K}^{+}$channel by a non-sulfonylurea compound KAD-1229 in a pancreatic beta-cell line, MIN 6 cell. Eur J Pharmacol 269: 293-298.

7. Bakkali-Nadi A, Malaisse-Lagae F, Malaisse WJ (1994) Ionophoretic activity of meglitinide analogues. Diabetes Res 27: 61-71.

8. Sunaga Y, Gonoi T, Shibasaki T, Ichikawa K, Kusama H, Yano H, Seino S (2001) The effects of mitiglinide (KAD-1229), a new anti-diabetic drug, on ATPsensitive $\mathrm{K}^{+}$channels and insulin secretion: comparison with the sulufonylureas and nateglinide. Eur $J$ Pharmacol 431: 119-125.
9. Reimann F, Proks P, Ashcroft FM (2001) Effects of mitiglinide (S 21403) on Kir6.2/SUR1, Kir6.2/SUR2A and Kir6.2/SUR2B types of ATP-sensitive potassium channel. Br J Pharmacol 132: 1542-1548.

10. Kawamori R, Kadowaki T, Onji M, Seino Y, Akanuma Y (2007) Hepatic safety profile and glycemic control of pioglitazone in more than 20,000 patients with type 2 diabetes mellitus: postmarketing surveillance study in Japan. Diabetes Res Clin Pract 76: 229-235.

11. Dormandy JA, Charbonnel B, Eckland DJA, Erdmann E, Massi-Benedetti M, Moules IK, Skene AM, Tan MH, Lefëbvre PJ, Murray GD, Standl E, Wilcox RG, Wilhelmsen L, Betteridge J, Birkeland K, Golay A, Heine RJ, Korányi L, Laakso M, Mokán M, Norkus A, Pirags V, Podar T, Scheen A, Scherbaum W, Schernthaner G, Schmitz O, Skrha J, Smith U, Taton J; PROactive investigators (2005) Secondary prevention of macrovascular events in patients with type 2 diabetes in the PROactive Study (PROspective pioglitAzone Clinical Trial In Macrovascular Events): a randomized controlled trial. Lancet 366: 1279-1289.

12. American Diabetes Association (2007) Standards of medical care in diabetes-2007. Diabetes Care 30 Suppl 1: S4-S41.

13. Risso A, Mercuri L, Quagliaro G, Damante G, Ceriello A (2001) Intermittent high glucose enhances apoptosis in human umbilical vein endothelical cells in culture. Am J Physiol Endocrinol Metab 281: E924-E930.

14. Assaloni R, Da Ros R, Quagliaro L, Piconi L, Maier A, Zuodar G, Motz E, Ceriello A (2005) Effects of S21403 (mitiglinide) on postprandial generation of oxidative stress and inflammation in type 2 diabetic patients. Diabetologia 48: 1919-1924.

15. Monnier L, Lapinski H, Colette C (2003) Contributions of fasting and postprandial plasma glucose increments to the overall diurnal hyperglycemia of type 2 diabetic patients. Diabetes Care 26: 881-885.

16. Fonseca V, Grunberger G, Gupta S, Shen S, Foley JE 
(2003) Addition of nateglinide to rosiglitazone monotherapy suppresses mealtime hyperglycemia and improves overall glycemic control. Diabetes Care 26: 1685-1690.

17. Jovanovic L, Hassman DR, Gooch B, Jain R, Greco S, Khutoryansky N, Hale PM (2004) Treatment of type 2 diabetes with a combination regimen of repaglinide plus pioglitazone. Diabetes Res Clin Pract 63: 127-134.

18. Rosenstock J, Gatlin MR, Shen S, Foley JE (2002) Combination therapy with nateglinide and a thiazolidinedione improves glycemic control in type 2 diabetes. Diabetes Care 25: 1529-1533. 